\title{
COVID-19 Timeline: Centers for Medicare and Medicaid Services (CMS) Changes and Primary Care Support Were Not Enough to Prevent Practice Losses
}

\author{
Christian Gausvik, MD and Yalda Jabbarpour, MD
}

(J Am Board Fam Med 2021;34:S7-S9.)

Keywords: Centers for Medicare and Medicaid Services, U.S., CoVID-19, Family Medicine, Health Policy, Primary Health Care, Telemedicine

The Coronavirus disease-19 (COVID-19) pandemic reaches back months on American soil and even farther globally. Though the far-reaching effects were unknown at the outset, many scholars correctly predicted that the US health care system was not prepared to effectively handle a pandemic of this magnitude. ${ }^{1}$ Although the focus of the shortcomings of our health care system has been on lack of personal protective equipment and intensive care unit capacity, the lack of support for primary care has been devastating. A primary care collaborative survey released in March showed 52\% of primary care providers reporting severe or close to severe financial effects on their practices due to COVID$19 .^{2}$ One week later results from the same survey reported $76 \%$ with severe or close to severe financial effects on their practices. Modeling analysts predict that this financial impact could lead to primary care shortages nationwide. ${ }^{3}$ Although the reasons for this financial impact are multifactorial and cannot be blamed on any single entity, we sought to

This article was externally peer reviewed.

Submitted 21 June 2020; revised 25 September 2020; accepted 29 September 2020.

From the Robert Graham Center for Policy Studies in Primary Care, Washington DC (CG, YJ); The Christ Hospital University of Cincinnati Family Medicine Residency Program, $\mathrm{OH}(\mathrm{CG})$.

Funding: None.

Conflict of interest: None.

Disclosures: None.

Corresponding author: Christian Gausvik, MD, The Christ Hospital, University of Cincinnati Family Medicine Residency Program, 2139 Auburn Ave, Cincinnati, OH 45219 (E-mail: christian.gausvik@gmail.com). understand how the timeline of Centers for Medicare and Medicaid Services (CMS) policy changes may have impacted primary care practices in the United States.

Using publicly available data on the CMS website we created a timeline of policy changes related to the COVID-19 pandemic, with a focus on reimbursement and telehealth changes. We also used publicly available data from the Centers for Disease Control and Prevention (CDC) to plot the number of COVID-19 cases against these CDC changes. Figure 1 details the timeline of some of the changes made to CMS juxtaposed with the disease progression.

Changes allowing for telehealth expansion came almost a month after the pandemic was predicted on March 17, 2020. Although these changes may have been fast by Medicare standards, the month delay between the formal World Health Organization pandemic announcement and CMS changes in the face of an unprepared system may have been too long for practices to wait. In fact, the primary care collaborative survey that showed severe financial effects on primary care practices nationwide was released just 2 days after telehealth expansion was finally announced. But perhaps more troubling was that the same survey showed that $70 \%$ of practices had no e-visit capability and $60 \%$ had no access to video visits. ${ }^{3}$ The CMS changes on March $17^{\text {th }}$ focused significantly on increasing the availability of telehealth reimbursement, but practices were not technologically configured to embrace this change from the inperson visits they financially relied on. By the time the April first data of the PCC (primary care 
Figure 1. A descriptive timeline of the changes made by Centers for Medicare and Medicaid Services (CMS) during the COVID-19 pandemic juxtaposed against popular events in the press at the time.
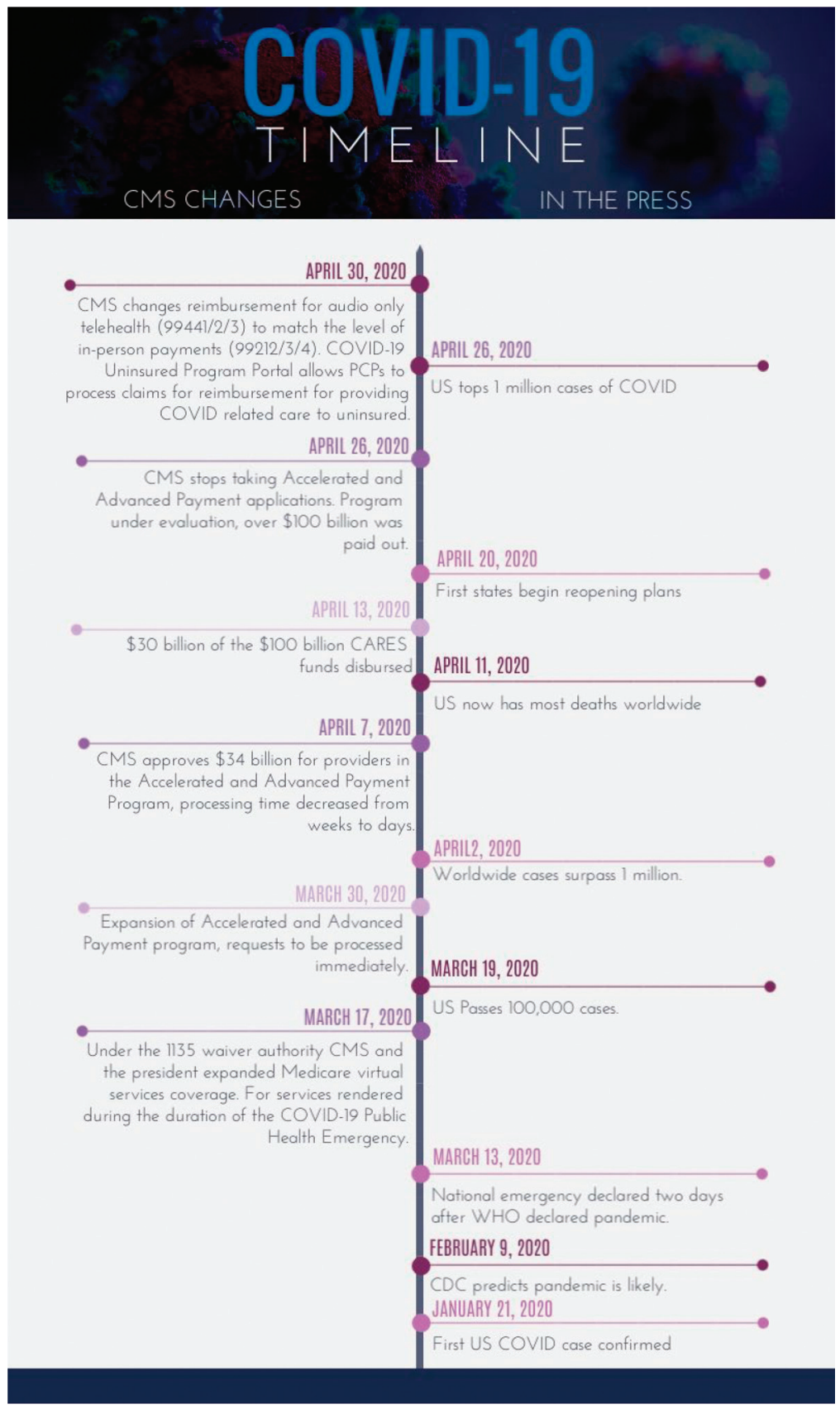

collaborative) report was released still nearly $40 \%$ of practices had no access to HIPAA-compliant video systems - the more highly reimbursed method of care delivery at that time - and only one third of practices felt they had enough cash on hand to keep their practices open for 4 weeks. ${ }^{3}$ Physicians in the survey reported increasing administrative burden with even less staff, and as noted in the timeline, efforts by CMS to ease paperwork requirements like Prior Authorizations did not go into effect until March $30^{\text {th }}$.
The Accelerated and Advanced Payment program, whereby practices could receive advanced payments based on prior claims data, went into effect on March $30^{\text {th }}$ with approvals following shortly after on April $7^{\text {th }}$ and payouts beginning on April $13^{\text {th }}$. This is a rapid turnaround, but even so, looking back at the survey data it is clear that for those practices unable to weather 4 weeks of financial strain it was too late. This underscores finances as one of the key reasons that Health Landscape data predicted a reduction of 
almost 20,000 Family Medicine Physicians and with them over 200,000 other jobs and over \$20 billion in lost wages. ${ }^{4}$ This projected loss accounted for an additional 287 counties across the country with a shortfall in health care providers - an over $25 \%$ increase in just 1 month. ${ }^{4}$ Granted not every closure is financial in cause, and perhaps not every closure is permanent, but even so, these losses occur at a time when we need medical care more than ever. The timeline illustrates a relatively quick pace of response, but reality shows us that this alone was not enough to save practices. What we need in the future is a more robust plan to support primary care when inperson visits rapidly decline.

A move toward value-based payments and alternative care delivery models would free primary care practices from some documentation burdens and allow for a more agile and financially sound pivot if in-person visits become a health risk in future crises. Here we might consider a practice model like ChenMed, a multi-state medical group serving vulnerable Medicare Advantage beneficiaries that do not depend on fee-for-service revenue. Without reliance on fee-for-service revenue, practices like ChenMed were able to weather the decline of in-person visits and not only survived but continued to open practices through COVID-19 instead of closing them. ${ }^{5}$

Shifts to value-based payment would have the added benefit of allowing practices to continue to financially support the telehealth services that have grown out of this current pandemic. Value-based practices such as ChenMed were able to convert 95\% of their visits to telehealth within 1 week. ${ }^{5}$ Telehealth is well received by patients with 1 study finding $95 \%$ satisfied with the care they received via a telehealth platform. ${ }^{6}$ Telehealth also represents a more efficient way to provide care for certain conditions, allowing for interval visits that are more convenient for patients and quicker for providers. Improving provider efficiency and providing primary care physicians with alternative, financially sound methods of caring for patients may even help reduce the burnout rates in primary care which are more than $50 \%$ today. ${ }^{7,8}$

Our ability to surmount health crises as they arise depends significantly on our ability to deliver effective primary care, and that means keeping practices open in the face of a dynamic economy and ensuring they are well equipped to provide care in flexible ways. The timeline presents the stark reality that crises evolve quickly. The data around primary care loss, the survey results from individual practices, and the realities of our health care system underscore the need for a more thoughtful approach to our future preparations. The future stability of primary care requires congressional changes to move us toward value-based care and investments in primary care infrastructure as well as a partnership from local and national health care systems to support these changes. ${ }^{9}$ Primary care is the backbone of our health care system and we have a responsibility to ensure we make changes to support it for the future.

To see this article online, please go to: http://jabfm.org/content/ 34/Supplement/S7.full.

\section{References}

1. Friedman U. We Were Warned. The Atlantic. Available at: https://www.theatlantic.com/politics/ archive/2020/03/pandemic-coronavirus-united-statestrump-cdc/608215/. Published March 18, 2020. Accessed June 15, 2020.

2. Coats DR. Worldwide Threat Assessment. Senate Select Committee on Intelligence. Available at: https:// www.dni.gov/files/ODNI/documents/2019-ATASFR-SSCI.pdf. Published January 29, 2019. Accessed June 15, 2020.

3. Primary Care \& COVID-19: Week 3 Survey. Primary Care Collaborative. Available at: https://www.pcpcc. org/2020/04/01/primary-care-covid-19-week-3-survey. Published June 18, 2020. Accessed June 15, 2020.

4. Coronavirus Pandemic-Related Potential Family Medicine Office Closures and Economic Impact. https://healthlandscape.org/covid19/. Published April 8, 2020. Accessed June 15, 2020.

5. Klein S, Hostetter M. Primary care as a bulwark against covid-19: how three innovative practices are responding. The Commonwealth Fund, Apr. 28, 2020. https://doi.org/10.26099/kxb8-j267.

6. Polinski JM, Barker T, Gagliano N, Sussman A, Brennan TA, Shrank WH. Patients' satisfaction with and preference for telehealth visits. J Gen Intern Med 2016;31:269-75. doi:http://dx.doi.org/10.1007/ s11606-015-3489-x.

7. Bodenheimer T. After COVID-19: how to rejuvenate primary care for the future. after covid-19: how to rejuvenate primary care for the future. Health Affairs. Available at: https://www.healthaffairs.org/ do/10.1377/hblog20200515.372874/full/. Published May 21, 2020. Accessed June 15, 2020.

8. New England Journal of Medicine Catalyst Team. What is telehealth? Available at: https://catalyst.nejm. org/doi/full/10.1056/CAT.18.0268. NEJM Catalyst. Published February 1, 2018. Accessed June 15, 2020.

9. Jabbarpour Y, Greiner A. Investing in primary care: a state-level analysis. Patient-Centered Primary Care Collaborative. July 2019. 